\title{
A novel scalable, robust downstream process for oncolytic rat parvovirus: isoelectric point-based elimination of empty particles
}

\author{
Barbara Leuchs $^{1}$ (D) • Veronika Frehtman ${ }^{1} \cdot$ Markus Riese $^{1} \cdot$ Marcus Müller $^{1}$ • \\ Jean Rommelaere ${ }^{1}$
}

Received: 12 October 2016/Revised: 15 December 2016 / Accepted: 17 December 2016 /Published online: 14 January 2017

(C) The Author(s) 2017. This article is published with open access at Springerlink.com

\begin{abstract}
The rodent protoparvovirus H-1PV, with its oncolytic and oncosuppressive properties, is a promising anticancer agent currently under testing in clinical trials. This explains the current demand for a scalable, good manufacturing practice-compatible virus purification process yielding high-grade pure infectious particles and overcoming the limitations of the current system based on density gradient centrifugation. We describe here a scalable process offering high purity and recovery. Taking advantage of the isoelectric point difference between full and empty particles, it eliminates most empty particles. Full particles have a significantly higher cationic charge than empty ones, with an isoelectric point of 5.86.2 versus 6.3 (as determined by isoelectric focusing and chromatofocusing). Thanks to this difference, infectious full particles can be separated from empty particles and most protein impurities by Convective interaction media ${ }^{\circledR}$ diethylaminoethyl (DEAE) anion exchange chromatography: applying unpurified $\mathrm{H}-1 \mathrm{PV}$ to the column in $0.15 \mathrm{M} \mathrm{NaCl}$ leaves, the former on the column and the latter in the flow through. The full particles are then recovered by elution with $0.25 \mathrm{M} \mathrm{NaCl}$. The whole large-scale purification process involves filtration, single-step DEAE anion exchange chromatography, buffer exchange by cross-flow filtration, and final formulation in Visipaque/Ringer solution. It results in $98 \%$ contaminating protein removal and $96 \%$ empty particle elimination. The final infectious particle concentration reaches $3.5 \mathrm{E} 10$ plaque forming units $(\mathrm{PFU}) / \mathrm{ml}$, with a specific activity of $6.8 \mathrm{E} 11 \mathrm{PFU} / \mathrm{mg}$ protein. Overall recovery is over $40 \%$. The
\end{abstract}

Barbara Leuchs

B.Leuchs@dkfz.de

1 German Cancer Research Center Tumor Virology F010, Im Neuenheimer Feld 280, 69120 Heidelberg, Germany newly established method is suitable for use in commercial production.

Keywords H-1 parvovirus · pI · Empty capsid elimination · Chromatography $\cdot \mathrm{CIM}^{\circledR}$ column $\cdot$ Upscaling

\section{Introduction}

Parvovirus H-1 (H-1PV) belongs to the family Parvoviridae (Cotmore et al. 2014). It consists of a non-enveloped icosahedral capsid $25 \mathrm{~nm}$ in diameter, containing a linear $\sim 5 \mathrm{~kb}$ single-stranded DNA genome. The viral DNA encodes nonstructural proteins-notably NS1 $(83 \mathrm{kDa})$ and NS2 $(25 \mathrm{kDa})$ - and the capsid proteins VP1 $(81 \mathrm{kDa})$ and VP2 $(65 \mathrm{kDa})$. VP3 $(63 \mathrm{kDa})$, another capsid protein, results from posttranslational cleavage of VP2, which takes place only in full particles (Faisst et al. 1995; Halder et al. 2012; Hanson and Rhode 1991). Although H-1PV is a rodent virus, it can infect and replicate in cells of a variety of vertebrates, including humans, and is known to exhibit oncolytic and oncosuppressive properties in a number of tumor models (Nuesch et al. 2012; Rommelaere et al. 2010). As a result of promising preclinical studies, the first in-man phase I/IIa clinical trial of H-1PV was conducted in 2011-2015 in patients with recurrent glioblastoma (Geletneky et al. 2012). At the moment, a second phase I/II clinical trial has been initiated in patients with inoperable metastatic pancreatic cancer (ClinicalTrials.gov Identifier: NCT02653313; manuscript in preparation).

For these trials, the H-1PV good manufacturing practice (GMP) batches were purified by density gradient centrifugation (Leuchs et al. 2016; Ungerechts et al. 2016); however, this method is limited in scale. Upscaling is needed for the next clinical trial phases. It is therefore necessary to establish a 
simple, efficient, robust, reproducible, and scalable chromatography-based purification process allowing elimination of empty capsids and protein impurities in one step, while promoting high recovery of infectious particles. Furthermore, purified H-1PV has ultimately to be formulated into Visipaque (48\% iodixanol in Ringer solution), where the virus has known stability and which is also an X-ray contrast reagent for drug visualization in the human body.

We describe here a scalable, reproducible, high-grade chromatography-based procedure for H-1PV purification. An important challenge is to eliminate empty particles which were assembled but in which viral DNA failed to be packaged. The known difficulty of separating empty from full (genomecontaining) particles by chromatography prompted us to first determine the isoelectric point difference between empty and full particles. In a second step, we exploited this difference to eliminate empty particles as well as protein contaminants by anion exchange chromatography, thus obtaining highly pure batches of infectious particles. Convective interaction media $\left(\mathrm{CIM}^{\circledR}\right)$ diethylaminoethyl (DEAE) monolith columns were used, as they achieve convective mass transport resulting in a high flow rate, yield, and efficiency. They also capture large molecules or particles such as H-1PV. What is more, these columns do not lose resolution upon upscaling (Rajamanickam et al. 2015).

\section{Materials and methods}

\section{Preparation of clarified H-1PV cell lysate}

H-1PV wild-type (wt) virus was produced in a 10-layer CellSTACK $^{\circledR}$ (CS; Corning, Wiesbaden, Germany) according to Leuchs et al. 2016. For this, NB-324K cells were seeded at $3.6 \mathrm{E} 4 \mathrm{cells} / \mathrm{cm}^{2}$ and infected immediately with $\mathrm{H}-1 \mathrm{PV}$ wt (Kestler et al. 1999) at a multiplicity of infection (MOI) of 0.01 plaque forming units (PFU) per cell. To generate the clarified cell lysate, the cells were harvested after 4 days of incubation, lysed in $50 \mathrm{mM}$ Tris-HCl (Trizma ${ }^{\circledR}$ hydrochloride; Sigma-Aldrich Co, St. Louis, USA) buffer, DNAsetreated $(50 \mathrm{U} / \mathrm{ml}$, Sigma-Aldrich Chemie GmbH, Steinheim, Germany), and filtered through 0.2- and 0.1- $\mu \mathrm{m}$ membranes (Sartorius AG, Göttingen, Germany).

The H-1PV is also publically available at ATCC ${ }^{\circledR}$ VR-356.

\section{Purification of H-1PV}

\section{IOD-PBS and VIS-Ringer density gradients}

Iodixanol-PBS (IOD-PBS) and Visipaque-Ringer (VISRinger) density gradient purifications were performed according to Leuchs et al. 2016 with $20 \mathrm{ml}$ clarified cell lysate.
$\mathrm{CsCl}$ density gradient

$\mathrm{CsCl}$ density gradient purification was performed according to Leuchs et al. 2016.

\section{Small- and large-scale DEAE anion exchange chromatography (AEX)}

All chromatographic studies were performed with a $0.34-\mathrm{ml}$ $\mathrm{CIM}^{\circledR}$ DEAE monolith disk or an 8-ml $\mathrm{CIM}^{\circledR}$ DEAE monolith column (1.3 $\mu \mathrm{m}$ pore size; Bia Separations, Ajdovscina, Slovenia) and ÄKTAprime (GE Healthcare Europe GmbH, Freiburg, Germany) at room temperature (RT) under laminar flow. The $\mathrm{CIM}^{\circledR}$ monolith is a single homogeneous piece cast from methacrylate polymers containing flow through pores. DEAE is a weak anion exchanger with a charged diethylamino group which selectively binds molecules with a predominant negative charge. The flow rate of the mobile phase was 0.7 or $2 \mathrm{ml} / \mathrm{min}$ depending on the column size. Absorbance was monitored at $280 \mathrm{~nm}$ and is expressed in milli absorbance units $(\mathrm{mAu})$. Conductivity is expressed in millisiemens (mS). All buffers and the sample were filtered through $0.2-\mu \mathrm{m}$ filters. The column was equilibrated with the application buffer prior to the start of each run, until constant conductivity and UV absorbance values were observed. Elution steps were followed by a high-salt wash with $1 \mathrm{M}$ $\mathrm{NaCl}$ (Sigma-Aldrich Chemie GmbH, Steinheim, Germany). The application buffer was $50 \mathrm{mM}$ Tris- $\mathrm{HCl}$ or $0.15 \mathrm{M} \mathrm{NaCl}$ in $50 \mathrm{mM}$ Tris- $\mathrm{HCl}$, adjusted to $\mathrm{pH} 8.7$. The sample was diluted in application buffer and applied to the column. This was followed by a wash with application buffer until baseline UV absorbance was reached. Elution was performed with a continuous salt gradient from 0 to $0.5 \mathrm{M} \mathrm{NaCl}$ in $50 \mathrm{mM}$ Tris$\mathrm{HCl} \mathrm{pH} 8.7$ or from 0.15 to $0.4 \mathrm{M}(0.3 \mathrm{M}$ for large scale $) \mathrm{NaCl}$ in $50 \mathrm{mM}$ Tris- $\mathrm{HCl} \mathrm{pH} \mathrm{8.7.} \mathrm{One-milliliter} \mathrm{fractions} \mathrm{were} \mathrm{col-}$ lected during the runs and analyzed for genome-containing particles (GP), physical particles (PP), and plaque forming units. Because plaque forming unit evaluation is a laborious cell-based method, it was done only in large-scale chromatographic experiments and for analysis of the final formulation, given the importance of the infectious virus titer in anticancer virotherapy.

\section{Formulation of purified H-1PV after the preparative DEAE column}

The H-1PV eluate from the DEAE column contained $0.25 \mathrm{M}$ $\mathrm{NaCl}$. To eliminate salt and formulate into Visipaque (48\% iodixanol in Ringer), it was necessary to perform buffer exchange into Ringer solution (AlleMan Pharma GmbH, Reutlingen, Germany) followed by formulation in Visipaque (48\% iodixanol in Ringer). 
For buffer exchange into Ringer solution, two approaches were used:

On the one hand, a 5-ml HiTrap ${ }^{\mathrm{TM}}$ desalting column (GE Healthcare Europe GmbH, Freiburg, Germany) was used with the ÄKTAprime system. HiTrap ${ }^{\mathrm{TM}}$ utilizes cross-linked dextran for size exclusion chromatography. The column was equilibrated first with five column volumes (CV) of Ringer solution. Then, the sample was injected into a 5-ml sample loop filled with Ringer solution, loaded onto the column, and eluted with two $\mathrm{CV}$ of Ringer solution. One-milliliter fractions were collected and analyzed for genome-containing particles and physical particles. On the other hand, $6 \mathrm{ml}$ Vivaspin ${ }^{\circledR}$ concentrators (cutoff $30 \mathrm{kDa}$; Sartorius AG, Göttingen, Germany) were used. The membrane ultrafiltration system was first sterilized with $70 \%$ ethanol for $20 \mathrm{~min}$, centrifuged at $3000 \times \mathrm{g}$, rinsed with $6 \mathrm{ml}$ sterile water for injection use, centrifuged again, and allowed to dry under laminar flow. Samples with a starting volume of about $1 \mathrm{ml}$ were pipetted into the concentrator, diluted 1:5 with Ringer solution, and centrifuged at $3000 \times g$ until the volume reached $1 \mathrm{ml}$. Samples with a starting volume of $2 \mathrm{ml}$ or more were first concentrated to $1 \mathrm{ml}$ and then diluted with Ringer solution. This was done three times so as to dilute the initial buffer 1:125 in Ringer solution. The last concentration step was carried out down to a sample volume of $\sim 300 \mu$ l. The refraction index of the sample was then measured with a digital refractometer AR200 (Reichert, Inc., Depew, NY, USA) and had to be that of Ringer solution (1.3342 \pm 0.0002$)$.

The samples in Ringer solution obtained by one of the above methods were mixed with Visipaque ${ }^{\mathrm{TM}} 320$ (contains $65.2 \%$ iodixanol; GE Healthcare Europe GmbH, Freiburg, Germany) to $48 \%$ iodixanol final concentration. The refraction index of the sample was then measured and had to be that of a $48 \%$ Visipaque solution $(1.41 \pm 0.005)$.

\section{Quantification and qualification of H-1PV batches}

Virus quantification and characterization were done by a plaque formation assay (for infectious particles), qPCR (for GP), H-1PV Capsid-ELISA (for PP), protein quantification and sodium dodecyl sulfate-polyacrylamide gel electrophoresis (SDS-PAGE) with silver staining, western blotting, and sterility assessment (see Leuchs et al. 2016 for method description).

\section{Electron microscopy}

Electron microscopic analysis of the purified virus batches was performed according to Leuchs et al. 2016 with a few minor modifications. A preincubation step with $0.05 \%$ BSA solution for $1 \mathrm{~min}$ was added before sample incubation as well as a virus deactivation step with $0.1 \%$ glutaraldehyde for 5 min after sample incubation. Photos were taken with a
Zeiss EM 900 transmission electron microscope (Carl Zeiss Microscopy GmbH, Jena, Germany) at 85,000× magnification.

\section{Determination of H-1PV pI}

\section{Isoelectric focusing}

Full and empty viral capsid preparations $(\mathrm{CsCl}$ density gradient purified) were separated in the electric field on the basis of their different isoelectric points ( $\mathrm{pI}$ values).

All materials used for isoelectric focusing were purchased from Serva Electrophoresis $\mathrm{GmbH}$, Heidelberg, Germany. The $0.9 \%$ agarose gels were cast on a GelBond film with added $2.5 \%$ Servalyt carrier ampholytes $\mathrm{pH}$ 5-8 forming a $\mathrm{pH}$ gradient in an electric field. Gel electrophoresis was performed with the electrophoresis power supply EPS $3500 \mathrm{XL}$ (Amersham Pharmacia Biotech Europe GmbH, Freiburg im Breisgau, Germany) under laminar flow. The system was cooled to $10^{\circ} \mathrm{C}$, and the cooling reagent Bayol $\mathrm{F}$ was applied to the ceramic cooling plate between the gel and the plate. Filter paper strips soaked in electrode solutions were applied between the gel and the electrodes to maintain a stable gradient. An acidic solution was used at the anode and a basic one at the cathode. A 10- $\mu$ l sample was placed on the gel surface by means of a silicon applicator strip with sample holes, laid on the gel surface. Separation conditions were as follows: isoelectric focusing of the sample at $250 \mathrm{~V}, 10 \mathrm{~mA}, 10 \mathrm{~W}$ for $10 \mathrm{~min}$; $500 \mathrm{~V}, 10 \mathrm{~mA}, 10 \mathrm{~W}$ for $20 \mathrm{~min}$; and $1000 \mathrm{~V}$, $10 \mathrm{~mA}, 10 \mathrm{~W}$ for $40 \mathrm{~min}$. Fixation and silver staining were performed according to Willoughby and Lambert 1983.

\section{Chromatofocusing}

Chromatofocusing is a protein separation technique in which proteins elute from the column according to their pI. Chromatofocusing of empty and full capsid virus preparations (CsCl density gradient purified) was done at RT under laminar flow with a Mono P 5/50 column (GE Healthcare Europe GmbH, Freiburg, Germany) and an ÄKTAprime equipped with a 500- $\mu$ l injection loop. Mono $\mathrm{P}$ is a weak anion exchanger charged with mixed quaternary and tertiary amines. The flow rate of the mobile phase was $0.7 \mathrm{ml} / \mathrm{min}$. The absorbance was monitored at $280 \mathrm{~nm}$. All buffers and the sample were filtered through $0.2-\mu \mathrm{m}$ filters. The application buffer was $0.025 \mathrm{M}$ triethanolamine (Sigma-Aldrich Chemie $\mathrm{GmbH}$, Steinheim, Germany) adjusted to $\mathrm{pH} 8.3$ (for full and empty preparations) or 9.5 (for unpurified cell lysate) with concentrated iminodiacetic acid (Santa Cruz Biotechnology, Dallas, USA). The elution buffer consisted of Polybuffer 96 and Polybuffer 74 (GE Healthcare Europe GmbH, Freiburg, Germany) was diluted according the manual's instruction in water for injection use, and the $\mathrm{pH}$ was adjusted to 5.0 (for full 
and empty preparations) or 3.5 (for unpurified cell lysate) with concentrated iminodiacetic acid. The descending linear $\mathrm{pH}$ gradients $(\mathrm{pH} 8$ to 5 for full and empty particle preparations and $\mathrm{pH} 9.4$ to 3.5 for unpurified cell lysate) were obtained according to Mono P 5/50 manufacturer's instructions. For this, the column was equilibrated with application buffer at a $\mathrm{pH}$ slightly above the highest $\mathrm{pH}$ required. The elution buffer (adjusted to the lowest $\mathrm{pH}$ required) was passed through the column to generate first a pre-gradient. This was followed by application of the sample diluted in application buffer. Further application of the elution buffer to the column resulted in a moving descending $\mathrm{pH}$ gradient. This elution procedure led to formation of a $\mathrm{pH}$ gradient from $\mathrm{pH} 8.0$ to 5.0 or from 9.4 to 3.5 with a $\Delta \mathrm{pH}$ of $0.1-0.3$ between fractions. Fractions of 0.5 or $1 \mathrm{ml}$ were collected and analyzed for GP and PP. The $\mathrm{pH}$ of the collected fractions was measured manually with a Mettler Toledo InLab Viscous Pro pH electrode.

\section{Results}

The aim of this study was to develop a purification process allowing separation of empty particles from particles containing a full genome and compatible with large-scale H-1PV production for clinical applications.

\section{Isoelectric point of $\mathrm{H}-1 \mathrm{PV}$ and process impurities}

In order to separate empty from full $\mathrm{H}-1 \mathrm{PV}$ wt viral particles, it was necessary to find an exploitable difference in their physical properties. Isoelectric focusing was performed on purified empty and full particle preparations to determine the respective isoelectric points of these particles. The results (Fig. 1) revealed a $\mathrm{pI}$ of 6.3 for empty particles and of 5.8-6.2 for full particles (with negligible contamination by empty capsids). To see if this $\mathrm{pI}$ difference might be exploited in purifying infectious virus (i.e., to eliminate empty particles and contaminating proteins), chromatofocusing was used. First, CsClpurified empty or full particle preparations were loaded onto a Mono P 5/50 column and eluted as described under "Materials and methods". By this procedure (Fig. 2a), chromatofocusing identified a pI of 6.3 for empty particles (PP-to-GP ratio 869; data not shown) and of 5.8-6.1 for full particles (PP-to-GP ratio $\sim$; data not shown), thus confirming the results obtained by isoelectric focusing. Furthermore, chromatofocusing was used to estimate the pI range of impurities (host cell proteins, FBS) present in the clarified cell lysate. A significant amount of impurities were eluted from the Mono $\mathrm{P}$ column at basic $\mathrm{pH}$ ( $\mathrm{pI}$ range 9.4 to 7 ). The PP-toGP ratio was 43 at $\mathrm{pH} 6.4$ versus 13 at near $\mathrm{pH}$ 5.7, in keeping with the $\mathrm{pI}$ values determined for empty and full particles.

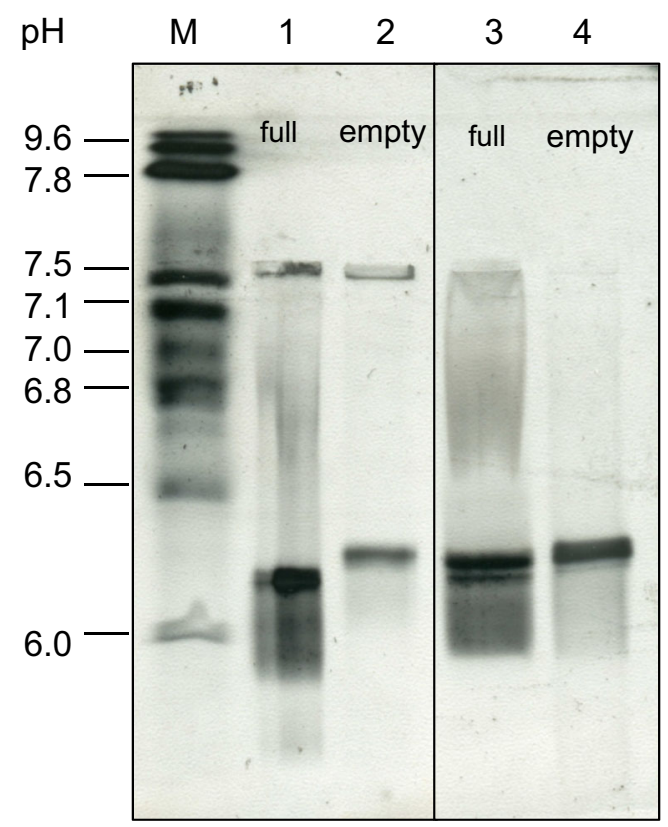

Fig. 1 Determination of the isoelectric points of H-1PV wt empty and full capsids by isoelectric focusing. Two independently purified batches of empty or full capsids were loaded on the $0.9 \%$ agarose gel and focused in the electric field according to their respective $\mathrm{pI}$ values. The bands were visualized by silver staining. $M$ indicates Biorad markers $\mathrm{pH}$ 4.45-9.6, lane 1 indicates full particles from batch 1, lane 2 indicates empty particles from batch 1 , lane 3 indicates full particles from batch 2 , and lane 4 indicates empty particles from batch 2

\section{Small-scale anion exchange (AEX) chromatography for determining optimal buffer and salt conditions}

The isoelectric points of proteins correlate with the charge at which they bind to/elute from the chromatography column. As the salt concentration increases, proteins with the weakest ionic interactions elute from the column first. With knowledge of the pI values of empty and full H-1PV particles and of the impurities arising during production, it is possible to separate these entities by AEX chromatography: most protein impurities should be eluted first, followed by empty particles and finally full particles.

As equilibration buffer for the AEX chromatography, $50 \mathrm{mM}$ Tris- $\mathrm{HCl} \mathrm{pH} 8.7$ was chosen for its compatibility with virus harvest. For optimal binding, in theory, the $\mathrm{pH}$ of the buffer has to be at least 1-2 $\mathrm{pH}$ units above the $\mathrm{pI}$ of the protein (Fekete et al. 2015). At pH 8.7, the impurities should not bind, as they are weakly negatively charged, neutral, or even positively charged ( $\mathrm{pI}$ between $\mathrm{pH} 9.5$ and 7.0). Since the $\mathrm{pI}$ is 6.3 for $\mathrm{H}-1 \mathrm{PV}$ empty particles and 5.8-6.1 for full particles, the virus is negatively charged at $\mathrm{pH}$ 8.7. Preliminary studies performed with different ion exchange columns to determine binding and elution conditions (data not shown) demonstrated that a weak anion exchanger (DEAE) column is the best choice for H-1PV purification. A 
a

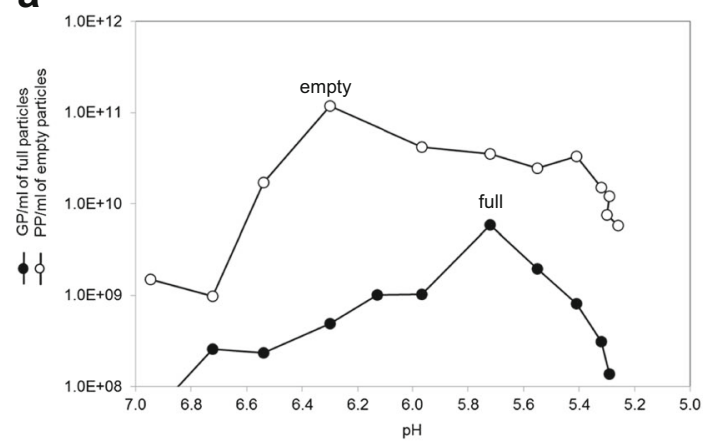

Fig. 2 pI profiles of empty and full H-1PV capsids (a) and impurities (b), obtained by chromatofocusing with a Mono P 5/50 column. The fractions were analyzed for genome-containing particles $(G P)$, physical particles $(P P)$, and protein content (protein impurities). a The isoelectric point of empty capsid particles is at $\mathrm{pH}$ 6.3, as depicted by the physical particle peak and as evidenced by the PP-to-GP ratio (not shown): ratio $\sim 869$ at

$\mathrm{CIM}^{\circledR}$ DEAE monolith column with a $1.3 \mu \mathrm{m}$ pore size was chosen for the chromatographic studies because of its ability to accommodate large molecules specifically while maintaining good mechanical stability.

Sodium chloride, sodium acetate, and ammonium acetate were tested to determine the best salt for elution. A mixture of pre-purified empty and full particles was applied to a 0.34-ml $\mathrm{CIM}^{\circledR}$ DEAE monolith disk and eluted with a continuous 0$0.5 \mathrm{M}$ gradient of the tested salt in $50 \mathrm{mM}$ Tris- $\mathrm{HCl} \mathrm{pH}$ 8.7. The peak fractions were analyzed for their PP and GP content. All elution profiles displayed two UV absorbance peaks: one corresponding to empty particles followed by one corresponding to full particles. As all the salts tested proved suitable for separating empty from full particles, we chose to continue working with $\mathrm{NaCl}$ because $\mathrm{H}-1 \mathrm{PV}$ is stable in $\mathrm{NaCl}$ solution (data not shown) and because $\mathrm{NaCl}$ is present in the desired final Visipaque/Ringer formulation $(0.053 \mathrm{M} \mathrm{NaCl})$. When a continuous gradient of $\mathrm{NaCl}$ was applied $(0-0.5 \mathrm{M} \mathrm{NaCl}$ in $50 \mathrm{mM}$ Tris- $\mathrm{HCl} \mathrm{pH}$ 8.7), the empty particles were eluted at $0.13-0.15 \mathrm{M} \mathrm{NaCl}$ (PP-to-GP ratio $\sim 300$ ) and full particles at $0.2-0.25 \mathrm{M} \mathrm{NaCl}$ (PP-to-GP ratio $\sim$ ) (Fig. 3a). As these salt concentrations could not be measured directly, the corresponding conductivity values were also measured (18-22 $\mathrm{mS}$ for empty particles and over $25 \mathrm{mS}$ for full particles) to ensure a reproducible purification process in further development experiments.

In a subsequent experiment, a small amount of clarified $\mathrm{H}-1 \mathrm{PV}$ harvest was prepared in $50 \mathrm{mM}$ Tris- $\mathrm{HCl} \mathrm{pH} 8.7$ with $0.15 \mathrm{M} \mathrm{NaCl}$ and loaded onto the $0.34-\mathrm{ml} \mathrm{CIM}^{\circledR}$ DEAE monolith disk to allow flow through of empty particles as well as impurities and binding of full particles to the column. The disk was then eluted with a $0.15-0.4 \mathrm{M} \mathrm{NaCl}$ gradient. As shown in the chromatogram of Fig. 3b, about $70 \%$ of the empty particles and $60 \%$ of the protein impurities were eliminated in the flow through and wash (first UV peak), whereas b

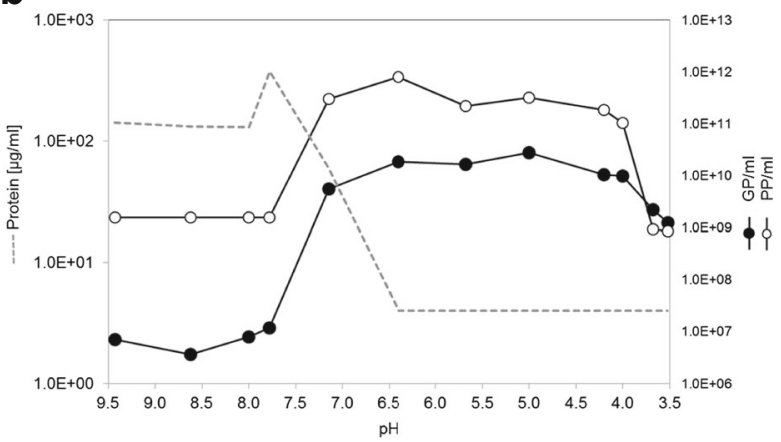

the $\mathrm{pH}$ corresponding to the PP peak. The isoelectric point of full capsid particles was around pH 5.6-6.1. The PP-to-GP ratio (not shown) was near 1 in this $\mathrm{pH}$ range. $\mathbf{b}$ The impurities in the clarified cell lysate (host cell proteins, FBS) showed isoelectric points between $\mathrm{pH} 9.5$ and 7.0, eluting from the Mono $\mathrm{P}$ column before $\mathrm{pH} 7.0$

about $60 \%$ of the full particles were eluted near $0.25 \mathrm{M} \mathrm{NaCl}$ (second UV peak).

\section{Reproduced large-scale single step AEX chromatography}

After determination of the optimal buffer and salt conditions, a large-scale purification was performed with clarified cell lysate from 2.3E8 cells (corresponding to the production of one 10-layer CS). Clarified cell lysate diluted in $50 \mathrm{mM}$ Tris-HCl pH 8.7 containing $0.15 \mathrm{M} \mathrm{NaCl}$ was loaded onto an 8-ml $\mathrm{CIM}^{\circledR}$ DEAE monolith column and eluted with a continuous salt gradient (0.15-0.3 M NaCl in $50 \mathrm{mM}$ Tris- $\mathrm{HCl} \mathrm{pH} \mathrm{8.7).}$ As seen in Fig. 4, empty particles were eluted in the flow through and wash (first UV peak) (PP-to-GP ratio near 50.0; $2.3 \mathrm{E} 14$ total PP). Full particles were eluted at $0.2-0.25 \mathrm{M}$ $\mathrm{NaCl}$ (conductivity 26-31.8 mS, second UV peak). The virus concentration was approximately $1 \mathrm{E} 13 \mathrm{GP} / \mathrm{ml}$ and $1 \mathrm{E} 10 \mathrm{PFU} /$ $\mathrm{ml}$ (data not shown) and the PP-to-GP ratio was about 1.

Chromatographic purification of clarified H-1PV cell lysate was reproduced for five individual batches. These experiments revealed elimination of $67 \pm 21 \%$ protein impurities and $65 \pm 28 \%$ empty particles, with recovery of $72 \pm 13 \%$ GP and $49 \pm 13 \%$ PFU (Table 1). The salt concentration required for full infectious particles was $0.2-0.25 \mathrm{M} \mathrm{NaCl}$, with a conductivity of 25-31.8 mS. Taken together, these results show that for the final formulation, it should be possible, in the future, to collect only one fraction, corresponding to this conductivity range.

\section{Buffer exchange and final formulation after AEX chromatography}

For the final formulation in Visipaque/Ringer solution, the full particle eluate from the DEAE column had first to be bufferexchanged into Ringer solution and finally mixed with 
a

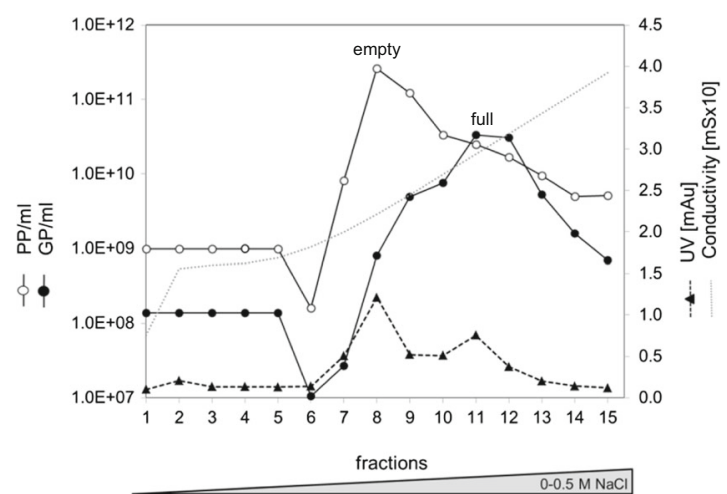

Fig. 3 Optimal buffer and salt conditions for DEAE chromatography. a Pre-purified empty and full $\mathrm{H}-1 \mathrm{PV}$ particles in $50 \mathrm{mM}$ Tris- $\mathrm{HCl} \mathrm{pH} 8.7$ were applied to the DEAE column and eluted with a continuous $0-0.5 \mathrm{M}$ $\mathrm{NaCl}$ gradient. The elution profile shows the elution of empty capsid particles in fraction 8 (first UV absorbance peak) with $0.15 \mathrm{M} \mathrm{NaCl}$ (conductivity $22 \mathrm{mS}$ ). The second UV absorbance peak, starting at fraction 11, shows desorption of full capsid particles at $0.2-0.25 \mathrm{M}$ $\mathrm{NaCl}$ (conductivity 29-32 mS). Physical particles $(P P)$ and genome- b

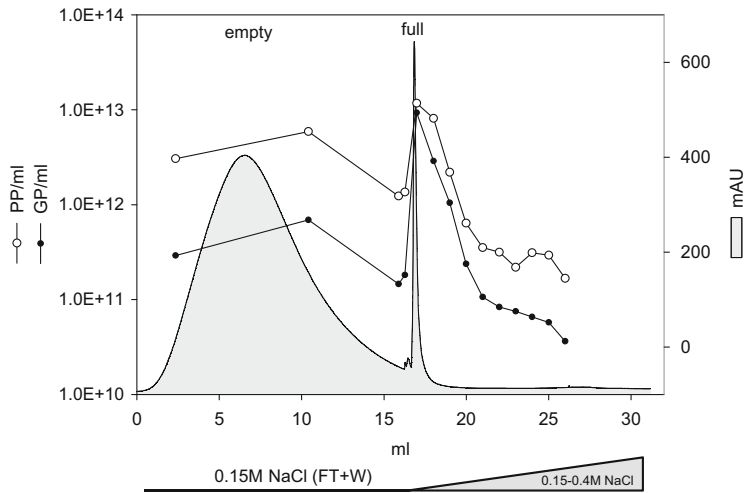

containing particles $(G P)$ were quantitated. b Clarified cell lysate was diluted in $50 \mathrm{mM}$ Tris- $\mathrm{HCl} \mathrm{pH} 8.7$ containing $0.15 \mathrm{M} \mathrm{NaCl}$ and applied to the DEAE column. Empty particles were recovered in the flow through and in the $0.15 \mathrm{M}$ wash (first UV absorbance peak). Upon elution with a $0.15-0.4 \mathrm{M} \mathrm{NaCl}$ gradient, full particles were eluted near $0.25 \mathrm{M} \mathrm{NaCl}$ (second UV absorbance peak). Physical particles $(P P)$ and genomecontaining particles $(G P)$ were quantitated

was similar (or even higher after Vivaspin ${ }^{\circledR}$ cross-flow filtration). The infectious virus titer obtained either by the standard method or by DEAE chromatography with Vivaspin ${ }^{\circledR}$ filtration was about $3 \mathrm{E} 10 \mathrm{PFU} / \mathrm{ml}$; after DEAE chromatography and HiTrap ${ }^{\mathrm{TM}}$ desalting, it was 3E9 PFU/ml. The three methods reduced protein impurities with equal effectiveness ( $>96 \%$ ), but chromatographic purification followed by either buffer exchange procedure eliminated empty particles more effectively ( $>95 \%)$ than the standard method $(85 \%)$. Virus purity, as determined by SDS-PAGE with silver staining, was the same after all three procedures (Fig. 5). Electron micrographs of the preparations obtained by the novel strategy
Fig. 4 Large-scale

chromatography of a $2.3 \mathrm{E} 8$ cell harvest (corresponding to one 10layer CellSTACK®, reproduced five times). When clarified cell lysate diluted in $50 \mathrm{mM}$ Tris- $\mathrm{HCl}$ pH 8.7 containing $0.15 \mathrm{M} \mathrm{NaCl}$ was loaded onto the 8-ml DEAE column, empty capsids was eluted in the flow through and wash (first UV peak). Full capsids was eluted in fractions $1-5$ at $\mathrm{NaCl}$ concentration $0.25 \mathrm{M}$ during elution with a continuous 0.15 $0.3 \mathrm{M} \mathrm{NaCl}$ gradient (second UV peak, PP/GP ratio $\sim 1$ )

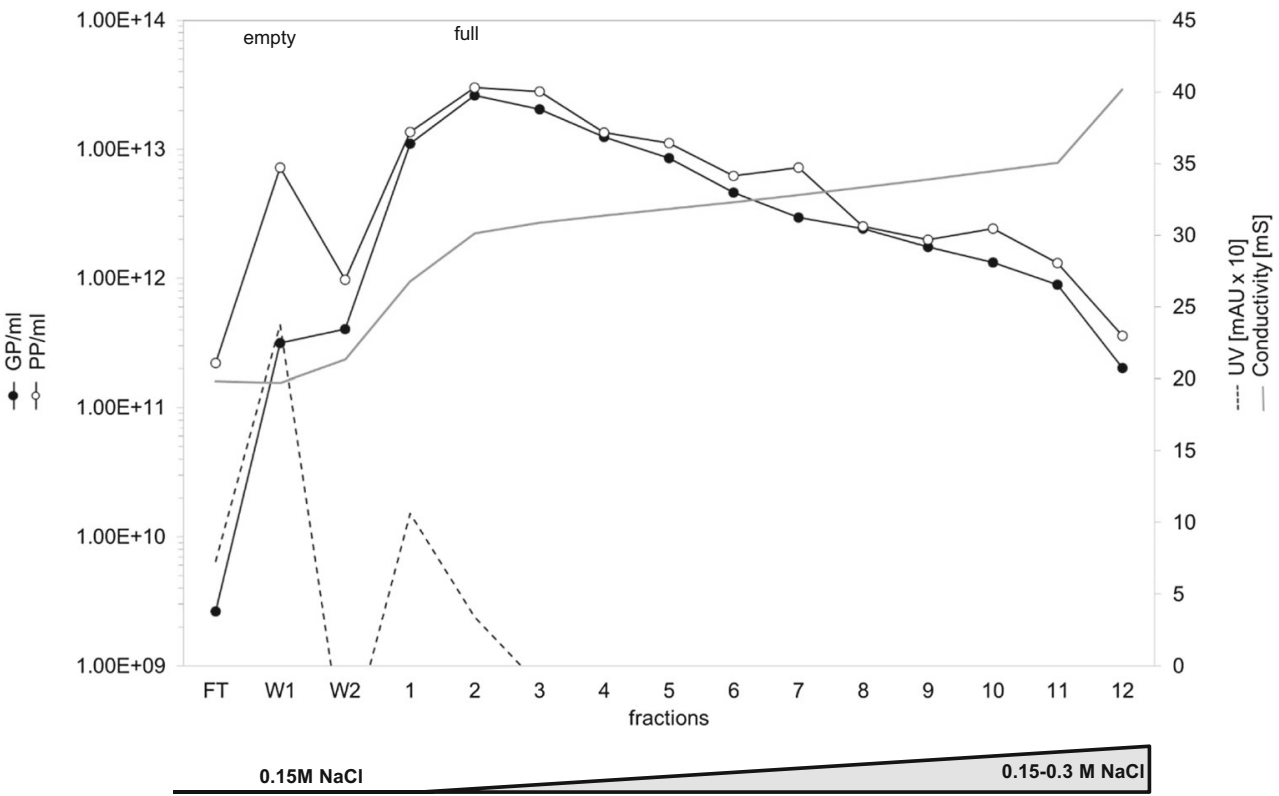


Table 1 Comparison of five individual chromatography batches

\begin{tabular}{lllll}
\hline Batch & $\begin{array}{l}\text { Depletion of protein } \\
\text { impurities [\%] }\end{array}$ & $\begin{array}{l}\text { Depletion of PP } \\
{[\%]}\end{array}$ & $\begin{array}{l}\text { Elution of GP } \\
{[\%]}\end{array}$ & $\begin{array}{l}\text { Elution of PFU } \\
\text { recovery [\%] }\end{array}$ \\
\hline 1 & 100 & 26 & 93 & 45 \\
2 & 72 & 53 & 74 & 55 \\
3 & 52 & 71 & 73 & 28 \\
4 & 47 & 100 & 64 & 60 \\
5 & 64 & 77 & 58 & 58 \\
Mean & $67 \pm 21$ & $65 \pm 28$ & $72 \pm 13$ & $49 \pm 13$ \\
{$[n=5]$} & & & & \\
\hline
\end{tabular}

Means with standard deviations for five independent chromatography runs showed full particles predominantly, in contrast to standard preparations. The flow diagram in Fig. 6 summarizes the downstream process steps of all three methods. Quality control tests demonstrated that all final formulated batches were sterile.

\section{Discussion}

In this study, we have developed a simple, scalable high-grade purification method for H-1PV. Empty particles are an undesirable by-product of H-1PV production, liable to cause an immune response without efficacy (Gao et al. 2014). Although ultracentrifugation-based methods have been used successfully to eliminate empty particles (Halder et al. 2012; Leuchs et al. 2016), these procedures are not scalable, they are only semi-sterile, and fractionation is less controllable than with chromatographic methods. This explains why it was urgent to develop new purification approaches suitable for upscaling.
As a basis for chromatographic purification, we first determined the pI values of empty and full particles: 6.3 and 5.86.1 , respectively. Isoelectric focusing and chromatofocusing gave similar results. For full particles, only a pI range could be obtained due to possible defective interfering virus particles (Faust and Ward 1979). Similar theoretical pI values were calculated for adeno-associated virus serotype 1 (pI, 6.3 for empty particles and 5.9 for full particles) (Venkatakrishnan et al. 2013). Knowledge of the isoelectric points of empty and full H-1PV was essential to developing the purification procedure and might have implications for virus interactions, stability, production, and in vitro studies (Xia 2007).

We have tested the ability of different chromatographic systems to eliminate empty particles and impurities. Unexpectedly, Capto Core 700, a chromatographic system combining size exclusion with anion exchange, failed to eliminate impurities under either acidic conditions (Ringer $\mathrm{pH}$ 5.6) or alkaline conditions (Ringer or $50 \mathrm{mM}$ Tris-HCl, $\mathrm{pH} 8.7$ ), as in both cases, most of the H-1PV was eluted at the cleaningin-place step with $1 \mathrm{M}$ salt wash or $1 \mathrm{M} \mathrm{NaOH}$ in $30 \%$ isopropanol. Slightly better results were obtained by applying
Table 2 Comparison of $\mathrm{H}-1 \mathrm{PV}$ recovery and depletion of empty particles as well as protein impurities by chromatographyand density gradient ultracentrifugation-based downstream process from the same starting material

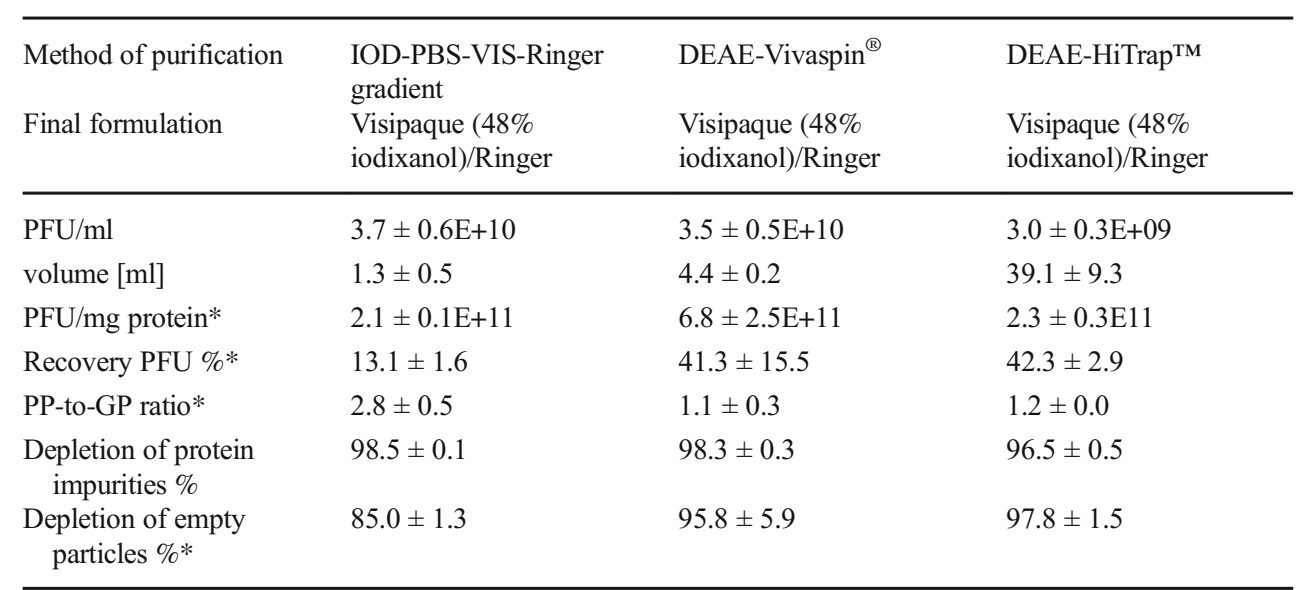

Means with standard deviations $(n=2)$ of infectious titer $(\mathrm{PFU} / \mathrm{ml})$, recovery of infectious particles*, specific activity* (PFU/mg protein), the PP-to-GP ratio*, and depletion of empty particles* and protein impurities. The $p$ value is $\leq 0.05$ for the features marked with asterisk. For $p$ value calculation, two further IOD-PBS-Vis-Ringer density gradient purified batches were taken into account 

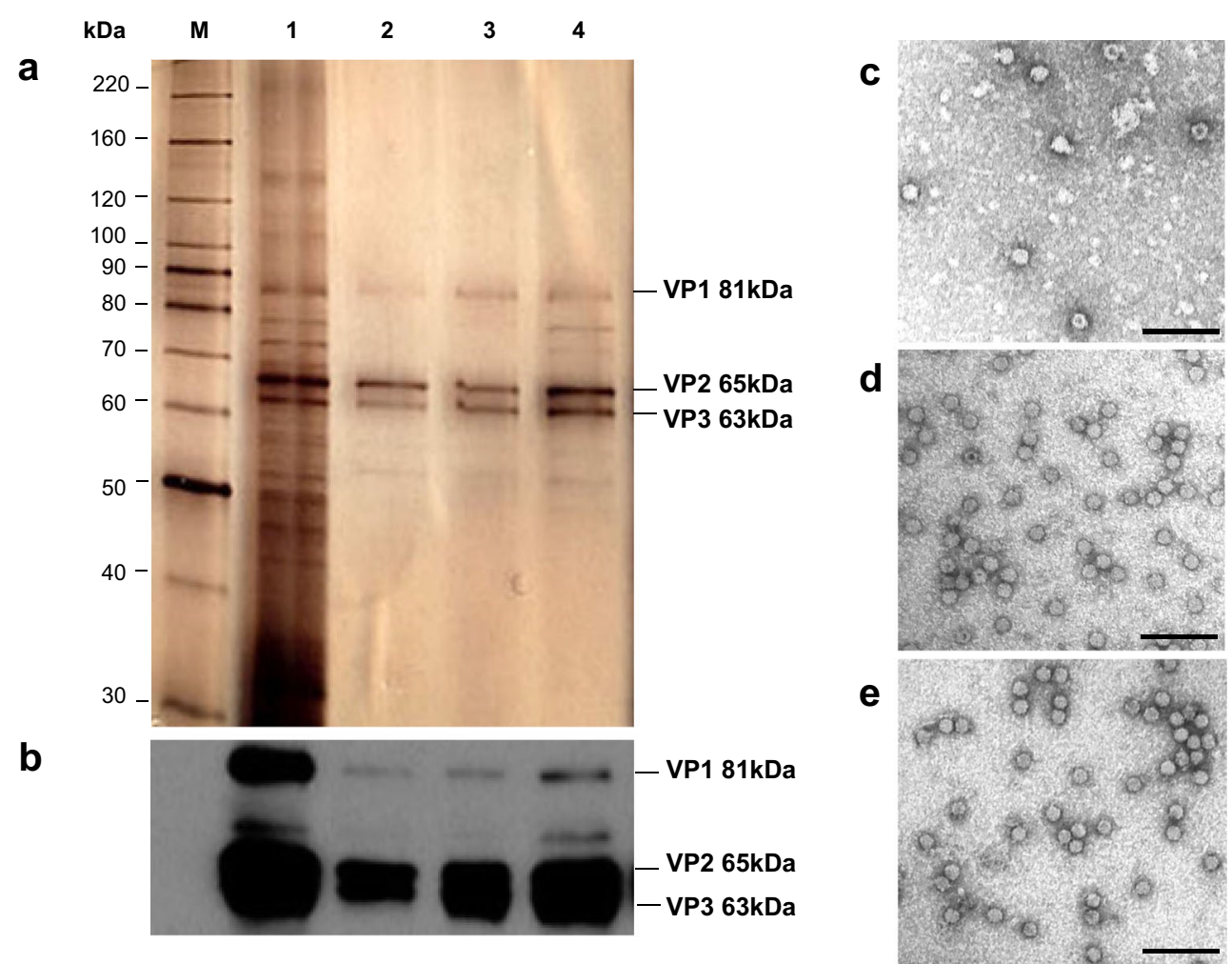

Fig. 5 Protein composition and electron microscope images of virus batches before and after the downstream process. a, b Protein extracts of virus samples (1.0E10 PP) were analyzed by SDS-PAGE and revealed by a silver staining or $\mathbf{b}$ immunoblotting with $\alpha \mathrm{VP}$ antibodies. $M$ indicates markers constituting the BenchMark ${ }^{\mathrm{TM}}$ Protein Ladder, lane 1

H-1PV diluted in Ringer solution ( $\mathrm{pH}$ 5.6): 17\% full particle recovery in the flow through (data not shown). This is in disagreement with the column manufacturer's claim that viruses and large molecules $\left(\mathrm{M}_{\mathrm{r}}>700 \mathrm{kDa}\right)$ are collected in the flow through (GE Healthcare, Application note 29-0983-01 AB). The H-1PV capsid, with a molecular weight of around 6E6 Da, should theoretically pass through the column. The reason for this failure of Capto Core 700 is unknown and was not further investigated. Binding studies with $\mathrm{H}-1 \mathrm{PV}$ have demonstrated that the virus binds to and elutes from both cation and anion exchangers, but best recoveries were achieved with AEX chromatography and elution at $\mathrm{pH} 8.7$ (data not shown). We were also able to purify $\mathrm{H}-1 \mathrm{PV}$ on a strong anion exchange column (QA), with similar full particle recovery (data not shown), but as no improvement over DEAE chromatography was observed in terms of recovery and protein impurity elimination, we decided to continue working with DEAE. Likewise, as sodium chloride, sodium acetate, and ammonium acetate in the eluent gave rise to similar resolution of the peaks corresponding to empty and full capsids, sodium chloride was chosen for H-1PV purification because $\mathrm{H}-1 \mathrm{PV}$ is stable in this salt and because $\mathrm{NaCl}$ is present in the final formulation. indicates virus harvest, lane 2 indicates IOD-PBS-VIS-Ringer, lane 3 indicates DEAE-VivaspinTM-final formulation, and lane 4 indicates DEAE-HiTrap-final formulation. $\mathbf{c}, \mathbf{d}$, e Electron micrographs showing clarified cell lysate (c), IOD-PBS-VIS-Ringer (d), DEAE-final formulation (e). Scale bar is $100 \mathrm{~nm}$

The fact that the pI difference between full and empty particles is at least $0.1 \mathrm{pH}$ unit has enabled us to develop a DEAE purification method. We show that $65 \%$ of the empty particles and $67 \%$ of the main impurities can already be eliminated in the flow through with $0.15 \mathrm{M} \mathrm{NaCl}$, and that $50 \%$ of the full infectious virus particles can be eluted with $0.3 \mathrm{M}$ salt. Thanks to the high stability of $\mathrm{H}-1 \mathrm{PV}$, the purification can be performed at room temperature (operating temperature $29 \pm 0.45^{\circ} \mathrm{C}$ ). Temperature, flow rate, and impurities influence the chromatography and should be taken into account for the reproducibility and robustness of the method (Mihelic et al. 2003; Acikara 2013).

With the present method and conditions, the H-1PV elution profile could not be reproduced with the closely related protoparvovirus minute virus of mice (MVM) (data not shown), and empty MVM particles could not be separated from full ones. The method as developed here is thus specific to $\mathrm{H}-1 \mathrm{PV}$.

Although the present method offers an H-1PV yield of nearly $50 \%$ from the clarified cell lysate, one should note that the medium supernatant of the upstream process is still routinely discarded, amounting to a $30 \%$ loss (Leuchs et al. 2016). To demonstrate proof of concept and to test the ability 


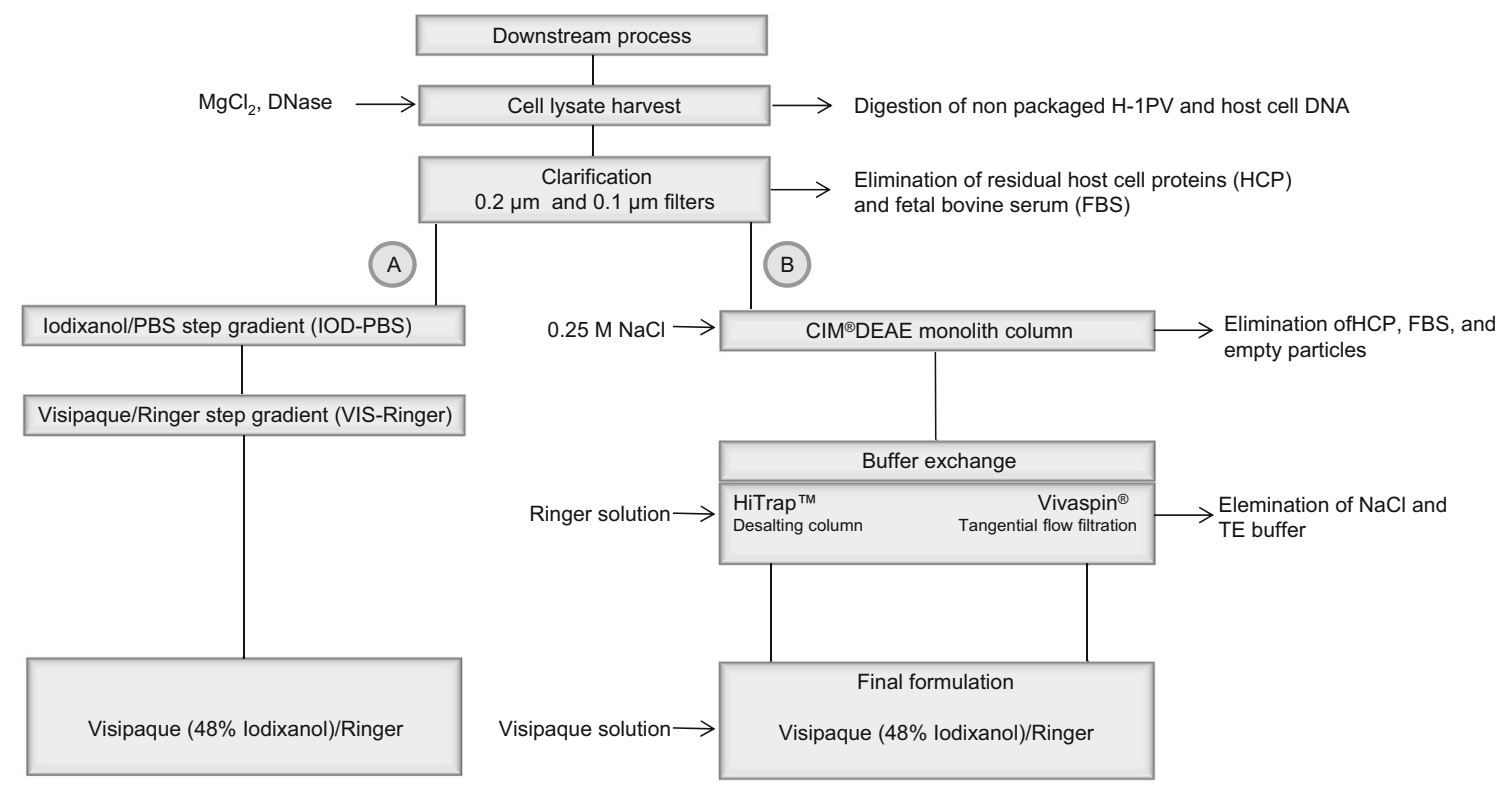

Fig. 6 Flow diagram of H-1PV downstream purification methods, comparing IOD-PBS-VIS-Ringer gradient purification with DEAE-final formulation methods

of our method to purify and concentrate H-1PV, clarified medium supernatant from routine production (corresponding to $1 / 10$ of a 10-layer CS production) was purified as described here. After DEAE purification, total PFU recovery was about $50 \%$, as observed with cell lysate, but the impurity content of $\mathrm{H}-1 \mathrm{PV}$ purified from culture medium supernatant was still high. Therefore, a second round of DEAE purification was performed, yielding $\sim 20 \%$ total PFU recovery in a 50th of the initial volume. Over $99.7 \%$ of the protein impurities were eliminated after the second DEAE purification step, so that the protein content was the same as for purified cell lysate (data not shown). Clearly, more optimization and upscaling will be required to include the medium supernatant in the complete downstream purification process in order to achieve a higher overall yield.

For the final formulation, both buffer exchange methods were suitable, but use of the Vivaspin ${ }^{\circledR}$ tangential flow filtration system to exchange the buffer and simultaneously concentrate the sample to the desired volume is optimal with negligible loss. Buffer exchange with the HiTrap ${ }^{\mathrm{TM}}$ desalting column leads to sample dilution and thus to a lower infectious virus titer in the final formulation. Between the two buffer exchange methods, there is a one-log infectious virus titer difference in the final formulation (3.5E10 and 3.0E9 PFU/ $\mathrm{ml}$ for Vivaspin ${ }^{\circledR}$ and HiTrap ${ }^{\mathrm{TM}}$ desalting, respectively).

The final novel downstream process, which achieves the target virus titer of $1 \mathrm{E} 10 \mathrm{PFU} / \mathrm{ml}$, involves the following steps: (1) DNase treatment to eliminate host cell DNA, (2) clarification $(0.2 \mu \mathrm{m}$ followed by $0.1 \mu \mathrm{m}$ filtration steps), (3) anion exchange chromatography to eliminate empty particles and most impurities, (4) a tangential flow filtration for buffer exchange and concentration, and (5) final formulation in Visipaque/Ringer solution.

As compared to iodixanol-based ultracentrifugation, use of this novel purification strategy involving monolith-based DEAE anion exchange chromatography significantly improves recovery and specific activity, leading to an optimal PP-to-GP ratio and significant elimination of empty particles ( $p$ values $\leq 0.05$ ). The performance of the new method is similar to that of the ultracentrifugation-based $\mathrm{CsCl}$ density gradient method, in terms of the PP-to-GP ratio and PFU per milligrams of protein (Leuchs et al. 2016). The virus titer of $1 \mathrm{E} 10 \mathrm{PFU} / \mathrm{ml}$ is optimal, because the virus particles start to aggregate at $1 \mathrm{E} 11 \mathrm{PFU} / \mathrm{ml}$ (as attested by high variance of the titer) and because preparations with a virus titer lower 1E8 PFU/ml are unstable over the years (data not shown). The overall recovery of $40 \%$ with our new purification strategy is comparable with or superior to those obtained in other virus/viral vector productions (Adamson-Small et al. 2016; Merten et al. 2016).

Upscaling for clinical applications is possible, with the larger CIM® DEAE monolith columns commercially available up to 81 . These could be loaded with a total of 5E14 PFU, (corresponding to 1000 10-layer CSs). Monolithic columns do not lose resolution with scale-up, so there is no need for new characterization studies. CIM® DEAE monolith columns offer a high binding capacity with high flow rates and low pressure (Mihelic et al. 2000), which could significantly reduce purification time and costs. Furthermore, these columns can be used as disposables or for multiple uses and as a single column or in multicolumn setups. As the limiting loading capacity of an $8-\mathrm{ml}$ column is $20 \mathrm{mg} \mathrm{BSA} / \mathrm{ml}$ and as we 
loaded such a column with only $\sim 15 \mathrm{mg}$ total protein (from cell lysate corresponding to $2.3 \mathrm{E} 8$ cells totaling about 5E11 PFU), the column could be loaded with 10 times as much. Furthermore, the tangential flow filtration is easily upscalable by using the proven polyethersulfone membrane with a pore size of $30 \mathrm{kDa}$. For upscaling, it is nevertheless necessary to establish the optimal flow rates and pressure.

In summary, we have developed a simple, robust one-step chromatography-based purification strategy enabling elimination of empty H-1PV particles and most impurities on the basis of their isoelectric points. This novel method offers sufficient recovery and maintains viral infectivity. It will facilitate aseptic upscaling according to GMP guidelines for clinical applications.

Acknowledgments The authors wish to thank Hans-Jürgen Engel, Barbara Liebetrau, and Silvia Münstermann for the experimental support and Serva Electrophoresis $\mathrm{GmbH}$ for the support in isoelectric focusing. They also express great appreciation to Mandy Roscher and Dr. Martin Müller for reviewing the manuscript.

\section{Compliance with ethical standards}

Conflict of interest The authors declare that they have no conflict of interest.

Ethical statement This article does not contain any studies with human participants or animals performed by any of the authors.

Funding This study was financially supported by Oryx GmbH \& Co.KG.

Open Access This article is distributed under the terms of the Creative Commons Attribution 4.0 International License (http:// creativecommons.org/licenses/by/4.0/), which permits unrestricted use, distribution, and reproduction in any medium, provided you give appropriate credit to the original author(s) and the source, provide a link to the Creative Commons license, and indicate if changes were made.

\section{References}

Acikara Ö (2013) Ion-exchange chromatography and its applications, column chromatography, Dr. Dean Martin (Ed.), InTech, DOI: 10.5772 /55744. Available from: http://www.intechopen.com/books/columnchromatography/ion-exchange-chromatography-and-its-applications

Adamson-Small L, Potter M, Falk DJ, Cleaver B, Byrne BJ, Clement N (2016) A scalable method for the production of high-titer and highquality adeno-associated type 9 vectors using the HSV platform. Mol Ther Methods Clin Dev 3:16031. doi:10.1038/mtm.2016.31

Cotmore SF, Agbandje-McKenna M, Chiorini JA, Mukha DV, Pintel DJ, Qiu J, Soderlund-Venermo M, Tattersall P, Tijssen P, Gatherer D, Davison AJ (2014) The family Parvoviridae. Arch Virol 159(5): 1239-1247. doi:10.1007/s00705-013-1914-1

Faisst S, Faisst SR, Dupressoir T, Plaza S, Pujol A, Jauniaux JC, Rhode SL, Rommelaere J (1995) Isolation of a fully infectious variant of parvovirus $\mathrm{H}-1$ supplanting the standard strain in human cells. J Virol 69(7):4538-4543

Faust EA, Ward DC (1979) Incomplete genomes of the parvovirus minute virus of mice: selective conservation of genome termini, including the origin for DNA replication. J Virol 32(1):276-292
Fekete S, Beck A, Veuthey JL, Guillarme D (2015) Ion-exchange chromatography for the characterization of biopharmaceuticals. J Pharm Biomed Anal 113:43-55. doi:10.1016/j.jpba.2015.02.037

Gao K, Li M, Zhong L, Su Q, Li J, Li S, He R, Zhang Y, Hendricks G, Wang J, Gao G (2014) Empty virions in AAV8 vector preparations reduce transduction efficiency and may cause total viral particle dose-limiting side-effects. Mol Ther Methods Clin Dev 1(9): 20139. doi: $10.1038 / \mathrm{mtm} .2013 .9$

Geletneky K, Huesing J, Rommelaere J, Schlehofer JR, Leuchs B, Dahm M, Krebs O, von Knebel Doeberitz M, Huber B, Hajda J (2012) Phase I/IIa study of intratumoral/intracerebral or intravenous/intracerebral administration of parvovirus $\mathrm{H}-1$ (ParvOryx) in patients with progressive primary or recurrent glioblastoma multiforme: ParvOryx01 protocol. BMC Cancer 12:99. doi:10.1186/1471-2407-12-99

Halder S, Nam HJ, Govindasamy L, Vogel M, Dinsart C, Salome N, McKenna R, Agbandje-McKenna M (2012) Production, purification, crystallization and structure determination of $\mathrm{H}-1$ parvovirus. Acta Crystallographica Section F-Structural Biology and Crystallization Communications 68:1571-1576. doi:10.1107 /S1744309112045563

Hanson ND, Rhode SL 3rd (1991) Parvovirus NS1 stimulates P4 expression by interaction with the terminal repeats and through DNA amplification. J Virol 65(8):4325-4333

Kestler J, Neeb B, Struyf S, Van Damme J, Cotmore SF, D’Abramo A, Tattersall P, Rommelaere J, Dinsart C, Cornelis JJ (1999) Cis requirements for the efficient production of recombinant DNA vectors based on autonomous parvoviruses. Hum Gene Ther 10(10):16191632. doi:10.1089/10430349950017626

Leuchs B, Roscher M, Muller M, Kurschner K, Rommelaere J (2016) Standardized large-scale H-1PV production process with efficient quality and quantity monitoring. J Virol Methods 229:48-59. doi:10.1016/j.jviromet.2015.11.022

Merten OW, Hebben M, Bovolenta C (2016) Production of lentiviral vectors. Mol Ther Methods Clin Dev 3:16017. doi:10.1038/mtm.2016.17

Mihelic, Koloini, Podgornik, Trancar S (2000) Dynamic capacity studies of CIM (convective interaction media)R monolithic columns. J High Resol Chromatogr 23(1):39-43. doi:10.1002/(SICI)1521-4168 (20000101)23:1<39::AID-JHRC39>3.0.CO;2-F

Mihelic I, Podgornik A, Koloini T (2003) Temperature influence on the dynamic binding capacity of a monolithic ion-exchange column. $\mathrm{J}$ Chromatogr A 987(1-2):159-168

Nuesch JP, Lacroix J, Marchini A, Rommelaere J (2012) Molecular pathways: rodent parvoviruses - mechanisms of oncolysis and prospects for clinical cancer treatment. Clin Cancer Res 18(13):3516-3523. doi:10.1158/1078-0432.CCR-11-2325

Rajamanickam V, Herwig C, Spadiut O (2015) Monoliths in bioprocess technology. Chromatography (2):195-212

Rommelaere J, Geletneky K, Angelova AL, Daeffler L, Dinsart C, Kiprianova I, Schlehofer JR, Raykov Z (2010) Oncolytic parvoviruses as cancer therapeutics. Cytokine Growth Factor Rev 21(2-3): 185-195. doi:10.1016/j.cytogfr.2010.02.011

Ungerechts G, Bossow S, Leuchs B, Holm PS, Rommelaere J, Coffey M, Coffin R, Bell J, Nettelbeck DM (2016) Moving oncolytic viruses into the clinic: clinical-grade production, purification, and characterization of diverse oncolytic viruses. Mol Ther Methods Clin Dev 3: 16018. doi: $10.1038 / \mathrm{mtm} .2016 .18$

Venkatakrishnan B, Yarbrough J, Domsic J, Bennett A, Bothner B, Kozyreva OG, Samulski RJ, Muzyczka N, McKenna R, AgbandjeMcKenna M (2013) Structure and dynamics of adeno-associated virus serotype 1 VP1-unique N-terminal domain and its role in capsid trafficking. J Virol 87(9):4974 4984. doi:10.1128/JVI.02524-12

Willoughby EW, Lambert A (1983) A sensitive silver stain for proteins in agarose gels. Anal Biochem 130(2):353-358

Xia X (2007) Protein isoelectric point bioinformatics and the cell, 1st edn. Springer, US, pp 207-219 